\title{
InfoNorth
}

\section{Predicting the Fitness Effects of Climate Change on Snowshoe Hares}

by Michael J.L. Peers

\section{INTRODUCTION}

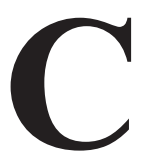

LIMATE CHANGE IS CONSIDERED ONE OF the greatest potential threats to global biodiversity (Thomas et al., 2004). Currently, it is altering the distribution and abundance of numerous species (Parmesan, 2006), causing numerical declines in populations that are unable to adapt (Kausrud et al., 2008) and potentially leading to species extinction (McLaughlin et al., 2002). Predicting the impacts of climate change on species demography, however, remains challenging because of the complexities associated with species' responses to shifting environments. One such complexity is how climate disruption affects biotic interactions (Heller and Zavaleta, 2009) and in particular, predator-prey dynamics (Post et al., 1999).

Predator-prey interactions are characterized by five stages (see Fig 1; adapted from Sih, 2011), and the likelihood of a prey being consumed is determined by the frequency of encounters and the conditional probability of each subsequent stage in the interaction. Therefore, climate change may reduce prey survival either by increasing encounter rates or by increasing the probability of any stage in the interaction. For example, increased snow depth caused wolves (Canis lupus) to hunt in larger packs, improving hunting success, which subsequently tripled kill rates of moose (Alces alces; Post et al., 1999).
Furthermore, warming temperatures increase swimming speed of northern pike (Esox lucius) relative to brown trout (Salmo trutta) and increase attack success (Öhlund et al., 2015). Most systems, however, consist of multiple predator species, and climate change may alter the relative importance of different predators to prey mortality rates through differential influences on any stage in the interaction (Fig. 1). This alteration may in turn influence future population dynamics of the prey. However, these complexities remain largely unexplored, because of the difficulties of simultaneously monitoring detailed changes in environmental conditions and cause-specific mortality of the target species.

The snowshoe hare (Lepus americanus) is a keystone prey species of the boreal forest (Krebs, 2011) and experiences regular population cycles that occur over 10-year periods (Krebs et al., 2001). Individual behaviour and population dynamics of hares are shaped heavily by predation, which can account for $85 \%-100 \%$ of mortalities in certain locations and years (Hodges, 2000). Changing winter conditions could be especially relevant for disrupting interactions between hares and their predators. Hares have a lower foot load than other species (Murray and Boutin, 1991), which provides them with an advantage over their predators in deep, soft snow. Changes in winter climate and the subsequent consequences for snow conditions could influence hare survival by altering predator hunting success

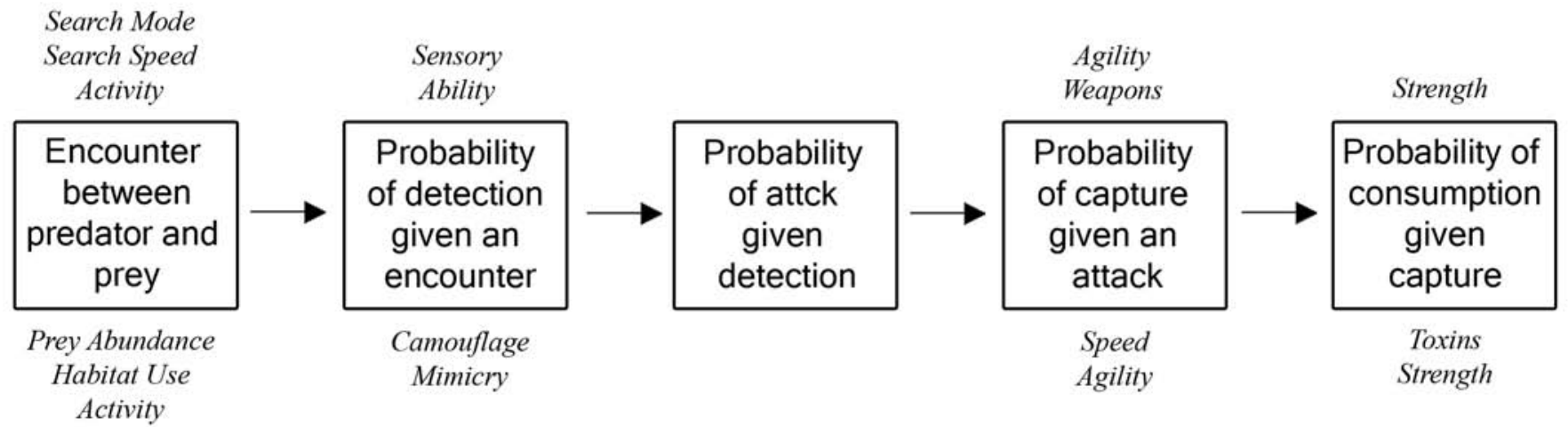

FIG. 1. The sequence of a predator-prey interaction starting with an encounter and proceeding to the consumption of prey (adapted from Sih, 2011). Climate change could influence prey mortality rates by increasing either encounters with predators or the probabilities of subsequent stages in the interaction. Also listed for each stage are traits of predators (above) and prey (below) that may influence these probabilities. 


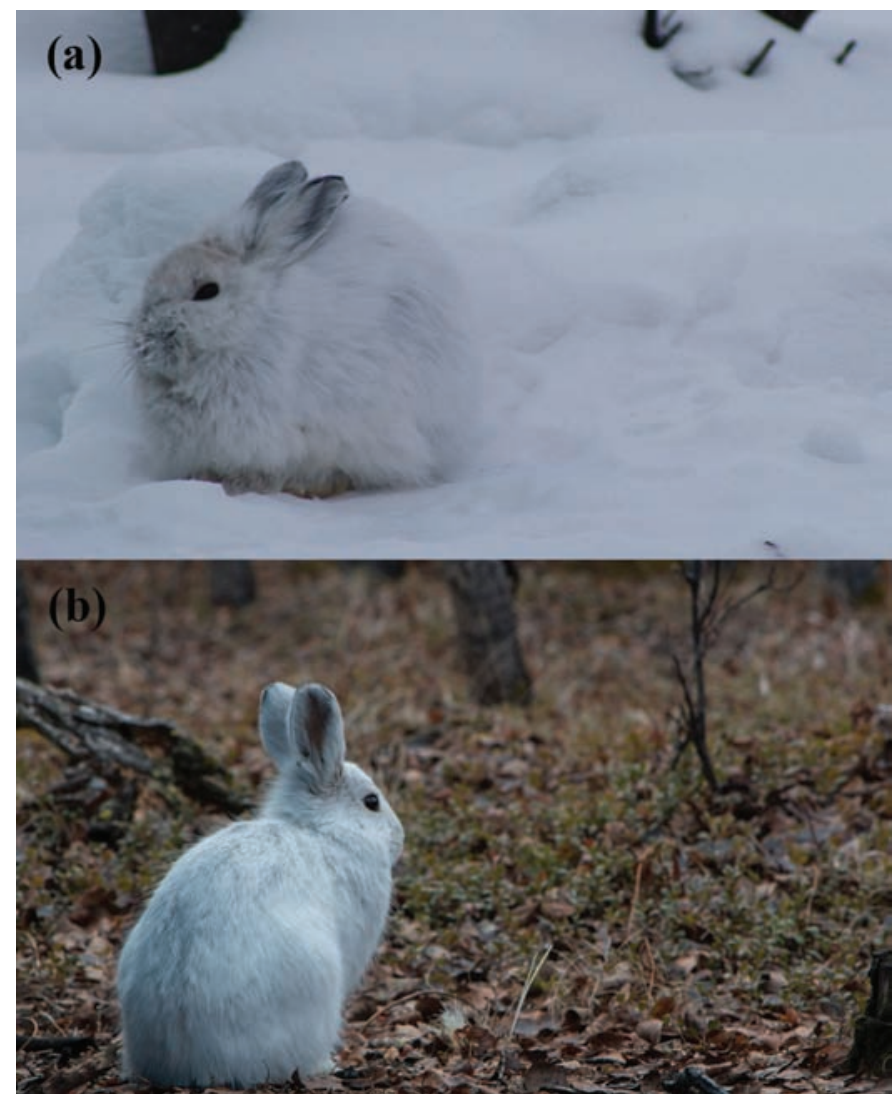

FIG. 2. Examples of a snowshoe hare that is a) completely matched, and b) completely mismatched. Photos by Yasmine Majchrzak and Eliot Linton.

(Stenseth et al., 2004), reducing the escape potential of hares, or changing encounter rates (Vucic-Pestic et al., 2011). To understand how climate variability affects snowshoe hares, we require detailed knowledge of both winter conditions and hare survival patterns.

Recent evidence suggests that climate change may further affect predator-prey dynamics for hares by reducing snow cover during the fall and spring. Hares undergo seasonal moults to a white or brown coat colour to match the presence or absence of snow. Later onset of snow in the fall and earlier spring melts would cause hares to be increasingly mismatched to their background under climate change, reducing their concealment from predators (see Fig 2; Mills et al., 2013). This mismatch limits cryptic abilities, increases detection by predators, and consequently affects survival (Zimova et al., 2016). However, understanding the complete impact of climate change-induced coat colour mismatch on hare demography requires a detailed understanding of the potential for phenotypic plasticity or microevolution in the phenology of coat colour moults in the species. Furthermore, we need to understand the total costs associated with camouflage mismatch, not just its effect on survival.

\section{RESEARCH METHODS AND QUESTIONS}

\section{Climate-Mediated Variability on Hare Survival}

All of my research has taken place in the Kluane Lake region of the Yukon. In this region, Canada lynx (Lynx canadensis) and coyote (Canis latrans) are the two major predators of hares, while Great-horned Owl (Bubo virginianus) and Northern Goshawk (Accipiter gentilis) account for a smaller percentage of deaths. In multi-predator systems such as this, climate change could alter the relative importance of certain predators as one species is increasingly favoured in response to climaterelated changes in risk. Such changes may arise from a temperature-related increase in mobility of prey that increases encounter rates with ambush hunters (Atwood et al., 2007). Additionally, certain predator species may have improved hunting success relative to other predators under particular climate conditions (e.g., snow hardness; Stenseth et al., 2004) that are expected to become more frequent over time. Such changes in risk may or may not increase overall mortality of the prey species depending on whether climate change leads to similar or inverse relationships in the consumption rate of each predator. Whether or not such climate variables increase overall mortality rates will determine their contribution to the population trajectory of the prey. My project will examine how different weather conditions influence mortality risk from each predator species in order to develop better understanding of how climate change may alter winter survival in hares.

The survival of individual hares has been monitored continuously over the last three winters using VHF telemetry (Fig. 3). At the same time, snow depth and hardness, daily snowfall, and temperature were recorded on each grid where hare survival was being monitored. When mortalities are determined through telemetry, carcasses are located as soon as possible to increase the likelihood of determining the cause of death for each individual. Snow depth and hardness are measured at each kill site, as well as at locations $10 \mathrm{~m}$ in each direction from the kill site. Although further work is required, preliminary analyses suggest that snow hardness affects hare mortality rates mainly through its effect on coyote predation risk.

\section{Individual Plasticity and Adaptive Potential}

Recent evidence suggests that hares have limited plasticity in their rate of colour change in the spring, but not in the fall rate, and not in the date the change initiates in either season (Mills et al., 2013; Zimova et al., 2014). The populations examined in these studies are expected to become severely mismatched over time (Mills et al., 2013). For at least one population, Zimova et al. (2014) observed large differences in completion dates for the colour change that matched differences in snow cover. However, population-level changes in phenology do not accurately estimate individual plasticity in the trait (Boutin 


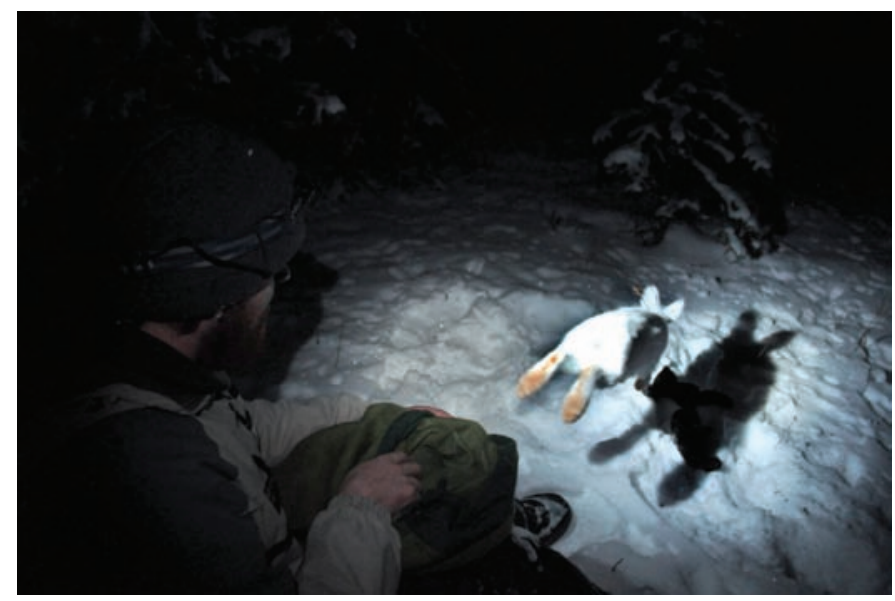

FIG. 3. Releasing a collared snowshoe hare on our study grid in the Kluane Lake region, Yukon. Photo by Kevin Chan.

and Lane, 2014). The few individuals that were monitored for consecutive years demonstrated large plasticity in colour change rates (i.e., 15-20 days; Zimova et al., 2014). This example indicates that we need to examine more populations to fully understand the plasticity of moulting rates in the species. Since 2015, the coat colour of individuals in the Kluane Lake region has been monitored once a week throughout the fall and spring moults using either trapping or telemetry. An array of trail cameras was established within the study area to monitor snow cover changes. I will examine how population and individual colour change rates vary across years and whether they match the yearly differences in snow cover. Large-scale trapping allowed for an increased number of individuals to be monitored across consecutive years to better our understanding of individual plasticity in moulting. Coincidently, the spring of 2016 was one of the earliest snow melts experienced in the Kluane Lake region, while 2017 was more representative of the past. This difference allows for a strong examination of individual plasticity in coat-colour change for the species.

Natural selection appears to have aligned the moult phenology of several lagomorph populations to their local climate (Watson, 1963; Nagorsen, 1983; Zimova et al., 2014). If coat-colour contrast has high survival costs (see Zimova et al., 2016), the large individual variation observed in coat-colour change suggests a potential for rapid adaptive evolution under climate change for populations not currently at risk. Snowshoe hares in the Kluane Lake region have been trapped regularly since 1986, providing a longterm dataset to examine whether coat-colour phenology has changed through time and whether these changes match changes observed in climate. Both the long-term data and the recent years of intensive trapping should allow for a strong understanding of the individual plasticity and adaptive potential of coat-colour change in the species.

\section{Fitness Costs of Coat-Colour Mismatch}

In order to examine the impact of climate change on hare demography, we require an understanding of the total costs associated with camouflage mismatch. Predators can influence prey through two pathways: 1) reducing prey density through consumption and 2) altering prey behaviour or physiology, which imposes fitness costs on the prey (Preisser et al., 2005; Creel and Christianson, 2008). Hares in the southern regions of their range have demonstrated lower weekly survival when camouflage is mismatched, with no behavioural plasticity to reduce these costs, and this situation is predicted to cause population decline in the future (Zimova et al., 2014, 2016). It is therefore imperative to determine whether hares in the core of their range experience the same mortality risk associated with increasing mismatch and the potential for mismatch to increase risk effects.

For example, if hares are exposed to higher predation risk when mismatched, individuals could reduce foraging (Lima and Bednekoff, 1999) and increase vigilance (Brown, 1999) to cope with increased risk, further affecting feeding rates and body condition of the individual. In tandem, increased detection by predators could result in higher frequencies of encounters and chases, which in turn could increase stress in hares (Sheriff et al., 2009). Since 2015, coat-colour mismatch has been determined for collared individuals using methods mentioned above, and using these data I can analyze the impact of this mismatch on survival. Some of these individuals have been equipped with GPS collars and accelerometers that measure fine-scale location and movement and can be used to monitor the behaviour of hares. Using this technology, I can examine whether hares modify behaviours (i.e., movement, vigilance) or habitat selection (i.e., forest type, snow cover) while mismatched, as well as the subsequent effects on foraging rates. Fecal samples from collared individuals collected during trapping sessions can be used to determine whether individuals experience increased predator-induced or nutritional stress while mismatched. This multifaceted approach provides a more comprehensive assessment of how increasing camouflage mismatch will affect snowshoe hare fitness.

\section{SIGNIFICANCE}

Predicting climate-driven impacts on snowshoe hare survival is especially important given the significance of hares as a food source in the boreal forest (Krebs, 2011) and the numerical response of several species to their fluctuating abundance (Boutin et al., 1995). The need to investigate these impacts is even more pressing since climate change seems to destabilize animal populations that display cyclic patterns in abundance similar to those of hares (Kausrud et al., 2008). This research will improve our ability to forecast climate change effects on snowshoe hares by determining the fitness consequences associated with 
climate change and the hares' ability to reduce these costs through individual plasticity and adaptation.

\section{ACKNOWLEDGEMENTS}

I am most honoured to have received the 2017 Jennifer Robinson Memorial Scholarship and would like to thank the selection committee and the Arctic Institute of North America for this award. I am grateful for the support and guidance from my supervisors Stan Boutin (University of Alberta) and Rudy Boonstra (University of Toronto). I want to thank graduate students Yasmine Majchrzak, Ally Menzies, and Emily Studd, as well as numerous field technicians who have helped with the project in so many ways. This project would not have been possible without their support. I would also like to thank Charles Krebs and Alice Kenney for their assistance on several aspects of the project, as well as their mentorship and encouragement throughout my time in Yukon. Thank you to Tom Jung, Dennis Murray, and Murray Humphries for offering financial and logistical support for my fieldwork.

Additional funding and support for this project came from the Natural Sciences and Engineering Research Council of Canada, the Northern Studies Training Program, the University of Alberta Northern Research Award program, the Association of Canadian Universities for Northern Studies, the Wildlife Conservation Society Canada, the W. Garfield Weston Foundation, the Killam Laureates program, and Earth Rangers.

\section{REFERENCES}

Atwood, T.C., Gese, E.M., and Kunkel, K.E. 2007. Comparative patterns of predation by cougars and recolonizing wolves in Montana's Madison Range. Journal of Wildlife Management 71(4):1098-1106. https://doi.org/10.2193/2006-102

Boutin, S., and Lane, J.E. 2014. Climate change and mammals: Evolutionary versus plastic responses. Evolutionary Applications 7(1):29-41. https://doi.org/10.1111/eva.12121

Boutin, S., Krebs, C.J., Boonstra, R., Dale, M.R.T., Hannon, S.J., Martin, K., and Sinclair A.R.E., et al. 1995. Population changes of the vertebrate community during a snowshoe hare cycle in Canada's boreal forest. Oikos 74(1):69-80. https://doi.org/10.2307/3545676

Brown, J.S. 1999. Vigilance, patch use and habitat selection: Foraging under predation risk. Evolutionary Ecology Research $1: 49-71$.

Creel, S., and Christianson, D. 2008. Relationships between direct predation and risk effects. Trends in Ecology \& Evolution 23(4):194-201. https://doi.org/10.1016/j.tree.2007.12.004

Heller, N.E., and Zavaleta, E.S. 2009. Biodiversity management in the face of climate change: A review of 22 years of recommendations. Biological Conservation 142(1):14-32. https://doi.org/10.1016/j.biocon.2008.10.006
Hodges, K.E. 2000. The ecology of snowshoe hares in northern boreal forests. In: Ruggiero, L.F., Aubry, K.B., Buskirk, S.W., Koehler, G.M., Krebs, C.J., McKelvey, K.S., and Squires, J.R. Ecology and conservation of lynx in the United States. Niwot: University Press of Colorado. 117-161.

Kausrud, K.L., Mysterud, A., Steen, H., Vik, J.O., Østbye, E., Cazelles, B., Framstad, E., et al. 2008. Linking climate change to lemming cycles. Nature 456:93-97.

https://doi.org/10.1038/nature07442

Krebs, C.J. 2011. Of lemmings and snowshoe hares: The ecology of northern Canada. Proceedings of the Royal Society B 278(1705):481-489. https://doi.org/10.1098/rspb.2010.1992

Krebs, C.J., Boonstra, R., Boutin, S., and Sinclair, A.R.E. 2001. What drives the 10-year cycle of snowshoe hares? Bioscience 51(1):25-35.

https://doi.org/10.1641/0006-3568(2001)051[0025:WDTYCO]2 $.0 . \mathrm{CO} ; 2$

Lima, S.L., and Bednekoff, P.A. 1999. Temporal variation in danger drives antipredator behavior: The predation risk allocation hypothesis. The American Naturalist 153(6):649-659. https://doi.org/10.1086/303202

McLaughlin, J.F., Hellmann, J.J., Boggs, C.L., and Ehrlich, P.R. 2002. Climate change hastens population extinctions. Proceedings of the National Academy of Sciences of the United States of America 99(9):6070-6074. https://doi.org/10.1073/pnas.052131199

Mills, L.S., Zimova, M., Oyler, J., Running, S., Abatzoglou, J.T., and Lukacs, P.M. 2013. Camouflage mismatch in seasonal coat color due to decreased snow duration. Proceedings of the National Academy of Sciences of the United States of America 110(18):7360-7365. https://doi.org/10.1073/pnas.1222724110

Murray, D.L., and Boutin, S. 1991. The influence of snow on lynx and coyote movements: Does morphology affect behavior? Oecologia 88(4):463-469.

Nagorsen, D.W. 1983. Winter pelage colour in snowshoe hares (Lepus americanus) from the Pacific Northwest. Canadian Journal of Zoology 61(10):2313-2318. https://doi.org/10.1139/z83-305

Öhlund, G., Hedström, P., Norman, S., Hein, C.L., and Englund, G. 2015. Temperature dependence of predation depends on the relative performance of predators and prey. Proceedings of the Royal Society B 282(1799): 20142254. https://doi.org/10.1098/rspb.2014.2254

Parmesan, C. 2006. Ecological and evolutionary responses to recent climate change. Annual Review of Ecology, Evolution, and Systematics 37:637-669.

https://doi.org/10.1146/annurev.ecolsys.37.091305.110100

Post, E., Peterson, R.O., Stenseth, N.C., and McLaren, B.E. 1999. Ecosystem consequences of wolf behavioural response to climate. Nature 401:905-907. https://doi.org/10.1038/44814

Preisser, E.L., Bolnick, D.I., and Benard, M.F. 2005. Scared to death? The effects of intimidation and consumption in predator-prey interactions. Ecology 86(2):501 -509.

https://doi.org/10.1890/04-0719 


\section{$434 \cdot$ INFONORTH}

Sheriff, M.J., Krebs, C.J., and Boonstra, R. 2009. The sensitive hare: Sublethal effects of predator stress on reproduction in snowshoe hares. Journal of Animal Ecology 78(6):1249-1258. https://doi.org/10.1111/j.1365-2656.2009.01552.x

Sih, A. 2011. Foraging theory. In: Scheiner, S.M., and Willig, M.R., eds. The theory of ecology. Chicago: University of Chicago Press. 65-90.

Stenseth, N.C., Shabbar, A., Chan, K.-S., Boutin, S., Rueness E.K., Ehrich, D., Hurrell, J.W., Lingjaerde, O.C., and Jakobsen, K.S. 2004. Snow conditions may create an invisible barrier for lynx. Proceedings of the National Academy of Sciences of the United States of America 101(29):10632 - 10634. https://doi.org/10.1073/pnas.0308674101

Thomas, C.D., Cameron, A., Green, R.E., Bakkenes, M., Beaumont, L.J., Collingham, Y.C., Erasmus, B.F., et al. 2004. Extinction risk from climate change. Nature 427(6970):145-148. https://doi.org/10.1038/nature02121

Vucic-Pestic, O., Ehnes, R.B., Rall, B.C., and Brose, U. 2011. Warming up the system: Higher predator feeding rates but lower energetic efficiencies. Global Change Biology 17(3):1301-1310. https://doi.org/10.1111/j.1365-2486.2010.02329.x
Watson, A. 1963. The effect of climate on the colour changes of mountain hares in Scotland. Journal of Zoology 141(4):823 - 835. https://doi.org/10.1111/j.1469-7998.1963.tb01629.x

Zimova, M., Mills, L.S., Lukacs, P.M., and Mitchell, M.S. 2014. Snowshoe hares display limited phenotypic plasticity to mismatch in seasonal camouflage. Proceedings of the Royal Society B 281(1782): 20140029. https://doi.org/10.1098/rspb.2014.0029

Zimova, M., Mills, L.S., and Nowak, J.J. 2016. High fitness costs of climate change-induced camouflage mismatch. Ecology Letters 19(3):299-307.

https://doi.org/10.1111/ele.12568

Michael Peers is the 2017 recipient of the Jennifer Robinson Memorial Scholarship. Michael is currently a doctoral student in the Department of Biological Sciences, University of Alberta. E-mail: michaeljlpeers@gmail.com 